\title{
1. Disrupting the aged care business model
}

\section{Erez Nusem, Cara Wrigley and Judy Matthews}

\section{INTRODUCTION}

The ageing population is a pervasive phenomenon affecting societies on a global scale. People can now expect to live longer than ever before, with physical and mental capabilities remaining high into old age (Clarkson et al., 2003). In most developed countries average life expectancy is rising at an almost linear fashion, with no sign of deceleration (Christensen et al., 2009). By 2050 there will be more people globally over the age of 60 than there will be under the age of 15 (Blythe et al., 2005). In addition to major economic implications (Clarkson et al., 2003), these changes present an increasingly discerning customer base, and major changes to regulations (King et al., 2012; Swan, 2010; Weerawardena and Mort, 2001).

A popular strategy, and the global direction of most governments to cope with the economic implications of an ageing population is to raise the typical retirement age (Christensen et al., 2009). However, this fails to address the fact that most elderly people aspire to actively participate in mainstream society, and reject the dependency and institutionalization typical of services in the last century (Clarkson et al., 2003). Most elderly individuals are healthy and possess a rich collection of skills, knowledge and expertise, they desire to be active and engaged, and assisting them in reaching this goal will have enormous economic benefits (Clare et al., 2010). The sheer number and proportion of elderly people, along with their collective spending power, provide an unprecedented business case for driving innovation in aged care (Clarkson et al., 2003).

Traditional approaches of determining value internally and simply presenting an offer to market are unlikely to see aged care providers through this phase of industry reform and changing customer demands (Nusem et al., 2015). Furthermore, while the relatively homogeneous aged care sector presents an opportunity for new entrants or forward-thinking organizations to disrupt the market and innovate in order to establish a competitive advantage, little existing literature explores an organization's 
role and capacity to assist in meeting this goal. Through a longitudinal action research methodology this chapter explores how can an aged care organization design a customer-centric business model and relevant value proposition for an ageing population?

This study is set against a growing body of work which calls to rethink traditional approaches to designing for social outcomes. Notably, Design for Public Good (UK Design Council et al., 2013) presents the value of utilizing a design-led approach to innovation in response to developing social challenges. The need for innovation in social services is, for the most part, heavily outlined in prevailing literature (Shin and Mcclomb, 2013; UK Design Council et al., 2013). Nonetheless, there exists a gap in concrete and practical tools, and guidelines for innovation, which integrate customer-centric approaches and methods for business model innovation (Maffei et al., 2005); a gap in research that is especially prevalent in an aged care context. This chapter highlights the challenges and opportunities presented by an ageing population, outlines the research design and methodology, summarizes the design framework utilized by a large non-profit aged care provider attempting to address these challenges and opportunities, presents the business model conceptualized through this study, and contributes an approach for organizations to innovate and design customer-centric business models.

\section{EMERGING VALUE OF DESIGN}

There is significant potential for innovation in the business models of aged care providers. Failing to innovate limits an organization's ability to meet challenges and generate new relevant services (Shin and Mcclomb, 2013), and while design has been demonstrated to be a crucial strategic business resource capable of driving innovation, conventional views continue to constrain design to its more traditional applications (Cox and Dayan, 2005; Dell'Era et al., 2010, p. 12). Furthermore, many organizations have limited access to innovation methodologies (Green et al., 2001), resulting in a need to develop innovation models for businesses (Maffei et al., 2005). Admittedly, the journey to success in the innovation of a business model is met with a multitude of barriers. In organizations that deliver social outcomes these barriers often manifest as: (1) inefficient handovers that occur between analysis, solution and implementation; (2) disjointedly patching together incremental solutions to problems as they arise; and (3) jumping straight to expensive or risky pilots (UK Design Council et al., 2013). As design offers (1) a collaborative approach, which (2) looks at an entire system and redefines the problem from the ground up, begins by 
understanding user needs in order to ensure that the solutions generated are appropriate to these needs, and (3) tests iteratively, starting with lowcost, simple prototypes and designing out risk as prototypes become more evolved (UK Design Council et al., 2013), it is an appropriate methodology for overcoming these challenges.

Innovation is a means to develop better ways of meeting customer needs, solving problems and using resources and technologies. Organizations must depend on successful innovation to thrive, but even in fields such as health care, innovation is often seen as a luxury or burden when it should be seen as a core activity (Burns, 2012; Mulgan and Albury, 2003). The associated challenges and benefits of innovating are widely understood, yet there remains little guidance and specific methods for approaching innovation in the face of emerging challenges.

\section{THE NEED FOR BUSINESS MODEL INNOVATION IN AGED CARE}

The global economy faces a number of complex challenges over the next 40 years, chief among them an ageing population, escalating levels of chronic illness and associated increases in health expenditure (King, 2007; Swan, 2010; Weerawardena and Mort, 2001). Reform initiatives, such as those introduced by the Australian Federal Government, seek to change the way that elderly people access, purchase and consume aged care services. These initiatives reflect shifting customer preferences and attitudes towards carerelated services (Weerawardena and Mort, 2001). Organizations failing to respond and innovate in light of these changing contexts may find their value offerings to be unsuitable in meeting emerging customer needs; new relevant models of care must inclusively address all dimensions of their customers' wellbeing. A key finding from Blythe et al.'s (2005) study was the need for aged care providers to shift from a medically oriented focus on care provision towards a customer-centric focus on quality of life. In turn, this would assist their customers' ability to remain independent and actively engaged, subsequently addressing the goal of maximizing the economic contribution of elderly people in society (Clarkson et al., 2003).

Aged care services are traditionally reactive, only addressing declines in wellbeing after associated challenges arise (Dwyer, 2011). This form of model does not promote independence and active engagement, which are integral elements to sustaining the wellbeing of elderly individuals, and key to assisting these individuals to continue living as productive and active members of mainstream society. From an economic standpoint, an aged care model that promotes wellbeing by proactively addressing potential 
declines in the physical and mental health of customers could enable increased quality of life and independence. This presents an opportunity to redesign the traditional value offered by aged care services. Design methodologies consider the customer's needs from the outset of a project rather than as an afterthought, and are intrinsically empathetic (Martin, 2009). Designers also employ divergent thinking and creative techniques that build a deeper understanding of customers, allowing for innovation to be approached in new ways (Carlopio, 2009). For these reasons a design-led approach to business model innovation was selected to drive this study in addressing the aforementioned challenges.

Increasingly, consumers of aged care are becoming discontented with a medical focus on care provision. This has resulted in a discrepancy between a provider's strategic intent, that is, the value delivered to customers, and what its customers require or expect, that is, its customers' needs (Goldstein et al., 2002, p. 124). As a design-led approach to innovation is inherently focused on the customer, it is appropriate for generating new concepts and more relevant models of care provision for customers (Maffei et al., 2005).

\section{RESEARCH DESIGN AND METHODOLOGY}

The first author, while working as a Design Innovation Catalyst (Wrigley, 2013) embedded in a large non-profit aged care provider for a period of two years, followed an action research methodology with a dual purpose; first, to design an innovative customer-centric business model for a nonprofit aged care organization; and second, to explore whether a design-led approach to innovation is appropriate in this context. As such, the research outlines two separate sets of data. One set collected by the organization for the purpose of designing an innovative customer-centric business model, and a second set collected by the first author for the purpose of gauging whether a design-led approach to innovation was appropriate for this undertaking. This section outlines the analysis methodology undertaken by the researchers, followed by the approach undertaken by the organization.

\section{Data Collection and Analysis}

Three methods of data collection were utilized by the first author to gauge the appropriateness of a design-led approach to innovation; these were semi-structured interviews, reflective journal entries and participant observation. Methodological triangulation of data collection was then used to increase the accuracy and validity of the collected data and findings (Guion et al., 2011). 
The first mode of data collection included two sets of semi-structured interviews. The initial set of interviews was exploratory, and primarily concerned with gathering insights regarding the participating organization and its competitors. These interviews were conducted at the beginning of the embedded practice period and consisted of 12 semi-structured interviews ranging between 30 to 90 minutes in length. The second set of interviews was focused, and predominantly explored participants' perceptions of the business model design, and whether the 24-month engagement had resulted in any tangible changes within the organization. This set of interviews was conducted at the end of the embedded practice period, and consisted of 21 participants, with the duration of the interviews ranging from 30 to 60 minutes.

Reflective journals were also kept by the first author as the second method of data collection. Writing down ideas and reflections was not simply a means of capturing them; the act in itself stimulated further thought and was a means for keeping the study on the researcher's mind (Watt, 2007). Through the use of a reflective journal, the first author was able to engage in ongoing dialogue with himself in order to better determine what the participating organization knew and more specifically how they believed they came to know it (Watt, 2007). This allowed for critical reflection of the design-led approach utilized by the participating organization.

Participant observation was used as the third mode of data collection. The aim of observing in this manner was to try to gain an understanding of the levels of engagement exhibited by external and internal stakeholders (Ballinger et al., 2004). This interpretive method was mindful of the fact that the researcher's comprehension of what is being observed was influenced by their own perspective and activities (Ballinger et al., 2004). Primarily, this method was used to identify whether participants were engaged during the discussion and contribution stages of the design and to scope how willing participants were to collaborate and contribute.

Data were thematically analysed and coded for categorization. Segments of text were labelled in accordance to the emergent categories for ease of retrieval and analysis of the data at a later stage (Joffe and Yardley, 2004). The codes were chosen to underpin the research and answer the research question. Since the researcher had already formed theoretical ideas in regards to the data, codes were applied deductively (Joffe and Yardley, 2004). Using theoretically derived themes allowed the researcher to replicate, extend or refute prior discoveries (Boyatzis, 1998). Emerging patterns in the data then confirmed the hypothesized themes and allowed for distinctions to be made between different aspects of the content. 


\section{Design Approach}

The research was conducted in a large non-profit aged care organization comprised of over 4000 employees, including a mix of permanent staff and volunteers, providing care services across three business streams (Home Care, Retirement Living and Residential Care) in over 30 locations on the Eastern seaboard of Australia. Realizing the need to innovate the value derived by its services the organization went about designing a new and innovative customer-centric business model over three cycles of action research, with each cycle of research aligning to key project outcomes (Table 1.1).

Cycle I was structured to internally demonstrate the value of design in a business context. This phase was about gathering a deep understanding of the organization's stakeholders, its internal and external environment and capturing a rich base of customer insights that would act as a foundation for future innovation. The purpose of Cycle II was to build momentum. This was achieved by identifying opportunities for innovation, conceptualizing what form the innovations could take and co-designing alternative service models to address the insights captured earlier in the study. Cycle III saw the organization shift away from a conceptual approach, and further design and launch the first business model prototype for testing.

Methods of data collection in each phase of the study are comprehensively detailed in Table 1.1 and below. The data were analysed thematically in stages as they were collected (Miles et al., 1994); patterns in the data were noted and themes were derived, checked for plausibility, clustered into groups, checked for consistency, contrasted and compared and variables in themes were partitioned. This stage of analysis condensed the bulk of the data and led to the finding of themes. The data were then classified and grouped by quantity; this entailed clustering existing clusters into larger groups. Since the organization had already formed theoretical ideas in regards to the themes, the data were deductively analysed; rather than 'reinventing the wheel', existing theories drove the questions investigated by the researchers, and researchers' understanding of the findings (Joffe and Yardley, 2004).

\section{Cycle I: Demonstrate}

The first cycle of the project was structured to gain a deeper understanding of the organization's internal environment and customer demographics. The organization conducted an in-depth customer segmentation study, analysis of its competitive environment and a set of narrative focus groups, 
Table 1.1 Overview of research cycles

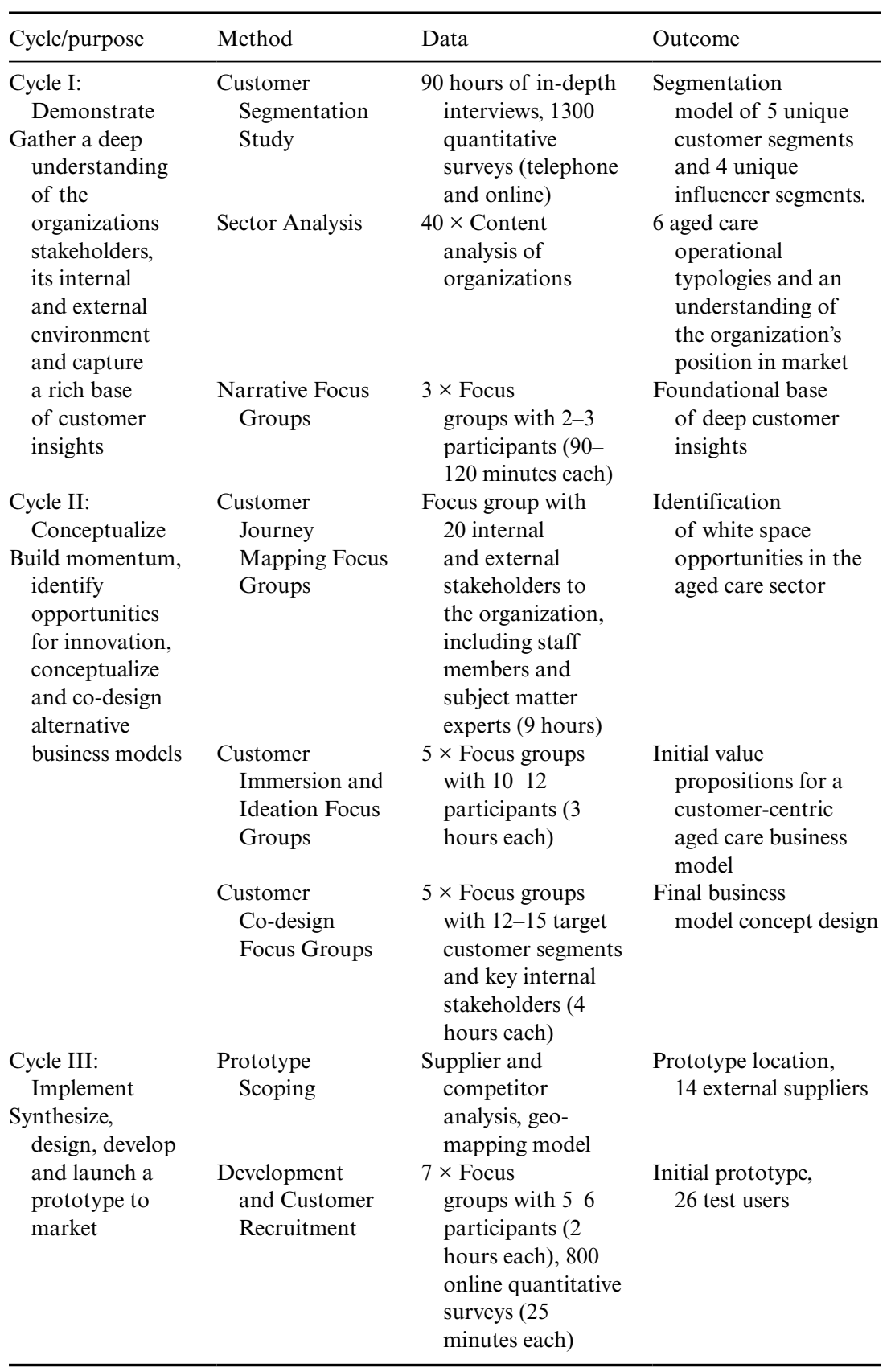


with the aim of testing assumptions and capturing a base of deep customer insights.

A behavioural segmentation study was carried out to collect both qualitative and quantitative data relating to the needs, preferences, attitudes, behaviours and decision-making approaches of ageing Australians and their families. Over 90 hours of customer interviews took place in metropolitan and regional areas across the Eastern seaboard of Australia, including 'High Tea Triads' (focus groups, typically with three to four participants), paired in-depth interviews and in-depth interviews.

The synthesized qualitative output informed the design of a quantitative data collection approach that incorporated over 1300 surveys deployed through both telephone and online methods. This staged research approach delivered a rich bank of qualitative and quantitative insights relating to the experience of ageing, as well as a segmentation model that clearly identified and described five unique customer segments and four unique 'influencer' segments. The findings of the segmentation study heavily informed and grounded the direction of the project. Primarily, the segmentation revealed two major clusters in the five customer segments; (1) the organization's existing customer base, with low levels of financial comfort and an external locus of control, and (2) the organization's desired customers, with high levels of financial comfort and an internal locus of control.

The preliminary stages of the sector analysis process consisted of the researchers using the business model canvas (Osterwalder and Pigneur, 2010) to analyse the business models of over 40 local and international organizations, both within and outside the aged care industry. For organizations in the aged care industry, the canvas was used to investigate: the common business model typologies utilized by aged care providers; the viability of existing aged care business model typologies; and the capacity of existing models of care in meeting the emerging needs of an ageing population. The organizations analysed outside the aged care industry were selected based on their exemplary performance in their given sectors. In this scenario the canvas was used to identify how these organizations were able to create, deliver and capture value, and, in a hypothetical context, how they would approach the delivery of aged care if they were to enter the market. This study resulted in a clearer understanding of the organization's competitors, along with the identification of six overarching aged care business model typologies.

Final stages of the first cycle saw the organization conduct a set of narrative focus groups, with an emphasis on co-designing with consumers. This process guided the testing of assumptions in regards to potential value propositions for new business models. Given that the definition of value and the process in which it is created is rapidly shifting from a 
product and firm-centric view to a personalized and customer-centric view, it was vital that the consumer became the locus of value creation and extraction (Osterwalder and Pigneur, 2010; Prahalad and Ramaswamy, 2004), as interacting with consumers through a co-design approach redefines the meaning of value and the process in which it is created (Prahalad and Ramaswamy, 2004).

The narrative was utilized to test customer insights, and conceptualize how these insights could be leveraged into new business models by iteratively challenging the organization's assumptions. Initial stages of the process involved using the Value Proposition Canvas (Osterwalder and Pigneur, 2010) to hypothesize unmet customer needs and to prototype ways of addressing those needs. The first author constructed and tested the narrative over three focus groups, each consisting of two to three participants in the organization's target demographic that were not receiving formal care services at the time. Following the narrative sessions, the insights were layered over the original Value Proposition Canvas to test the accuracy of the initial hypothesis. The insights were reframed, compared to the initial set, placed into a Business Model Canvas (Osterwalder and Pigneur, 2010) and compared to the existing business model in terms of financial and organizational capability to execute the model.

\section{Cycle II: Conceptualize}

The purpose of the second cycle of the project was to build momentum, identify opportunities for innovation and finally conceptualize and codesign alternative customer-centric aged care business models. During this cycle of the study the organization undertook customer journey mapping exercises and a series of three focus group typologies in order to design a new conceptual service offering. These were: a Customer Journey Mapping focus group, Customer Immersion and Ideation focus groups and Customer Co-design focus groups. The Customer Journey Mapping focus group was attended by 20 internal and external stakeholders to the organization, including staff members and subject matter experts. Through a series of activities and interactive sessions, participants created a large-scale visualization of a person's experience of ageing, focusing on dimensions of the experience that were reported as being significant in the segmentation study (Nusem et al., 2014). The goal of this focus group was to: identify the primary customer, secondary customer and relevant stakeholders; understand the needs and desires of the customer throughout each specific experience; articulate the channels in which the customer could be reached in terms of both potential interactions and platforms; unpack the experience, looking at dialogue, access, risk and transparency; identify the distinctive 
capabilities an organization would require to operate in the space; and validate potential sources of revenue generation. Participants were encouraged to deconstruct and analyse the ageing experience through the eyes of one of five identified customer segments and one of four identified influencer segments. In addition to building empathy with the customer and uncovering deeper insights into the experience of ageing, the focus group was designed to identify opportunities for relieving pain points or delivering greater value; this was especially valuable in identifying white space for new business model opportunities in the aged care sector.

Outputs from the Customer Journey Mapping focus group informed the design of a series of Customer Immersion and Ideation focus groups. Based on the segmentation model from Cycle I, a segmentation algorithm and selection questionnaire were employed to recruit ten to twelve participants per focus group, enabling the researchers to observe the focus group interactions on a segment-by-segment basis. Five dimensions of the ageing experience were explored (for example, 'Staying Connected'), one dimension per focus group, through open questioning and a structured but informal conversation with and amongst participants. Two types of questions were included in the focus group facilitator guide; those that deeply explored the topic and those that opened up the ideation process by encouraging participants to consider new solutions to problems. Analysis and synthesis of focus group outputs took place following the Customer Immersion and Ideation focus groups and findings were incorporated into a bank of prospective solutions that would form the basis of potential new business models.

A categorization and filtering process was applied to narrow the solutions to those that most effectively responded to the customer pain points and opportunities. These solutions were explored through a series of Customer Co-design focus groups. Participants were again recruited by segment, including customer and 'influencer' segments, and the approach to questioning was open-ended and exploratory. Large-scale visuals were used to describe the 'problem-solution' in a bare-bones fashion, and to deconstruct and reconstruct the solution with the participants as active designers. The zenith of this cycle saw the end of ideation and the conceptualization of a customer-centric business model.

\section{Cycle III: Implement}

The third cycle of the project saw the organization synthesize, design, develop and launch a prototype to market. A geo-mapping model was used to select the initial launch site for the service prototype and development site. The model was used to identify areas with high population density and large concentrations of elderly individuals (potential 
customers). Furthermore, the project team was embedded in the prototype suburb during this cycle of the project. This allowed for immersion in the community, providing invaluable insights into the lifestyle and motivations of potential customers.

First stages of this cycle of design saw the team conduct a market analysis of potential suppliers (partners) and competitors. The prototype solution was then further defined and built. Elements of this stage of design included an online portal, engagement plan, supplier partnering and staffing structure. To ensure that the prototype solution was loyal to the initial insights captured with customers, the study team conducted seven focus group sessions with approximately 40 participants from the organization's desired customer segment. The purpose of the focus groups was to detail the conceptual model in accordance to customer preferences, and build a Minimum Viable Product (Maurya, 2012) for testing.

An online quantitative survey was also administered to over 800 individuals recruited based on the segmentation study. The survey was structured to capture perceptions regarding the offering and brand of the initial prototype. This included understanding the healthy ageing behaviours, consideration and propensity to pay, optimal method and channel for engagement, levels and types of chronic disease along with how they are managed, education and employment status, life transitions and experiences, and location density of the organization's target customer segment. Finally, the prototype was launched with 26 test users and 14 external suppliers across two suburbs with high concentrations of the organization's target customer segments.

\section{THE BUSINESS MODEL}

As illustrated in Figure 1.1, this research contributes a new aged care business model that seeks to fundamentally redefine the experience of ageing. Under the new model customers are engaged earlier in life and guided to extend their healthy and productive life expectancy through advice, motivation and connection to proactive health and wellbeing services. Due to the scope and size of the organization, and the risks associated with driving change in larger businesses, the new prototype was launched as a standalone entity. While the organization has begun to offer the new value proposition to market, the core business continues to engage with customers in times of need through a traditional reactive model. By offering a range of health and wellbeing services that extend healthy life expectancy, the participating organization challenges the assumptions of ageing, looking to disrupt its more traditional services and the sector in which they are offered. 

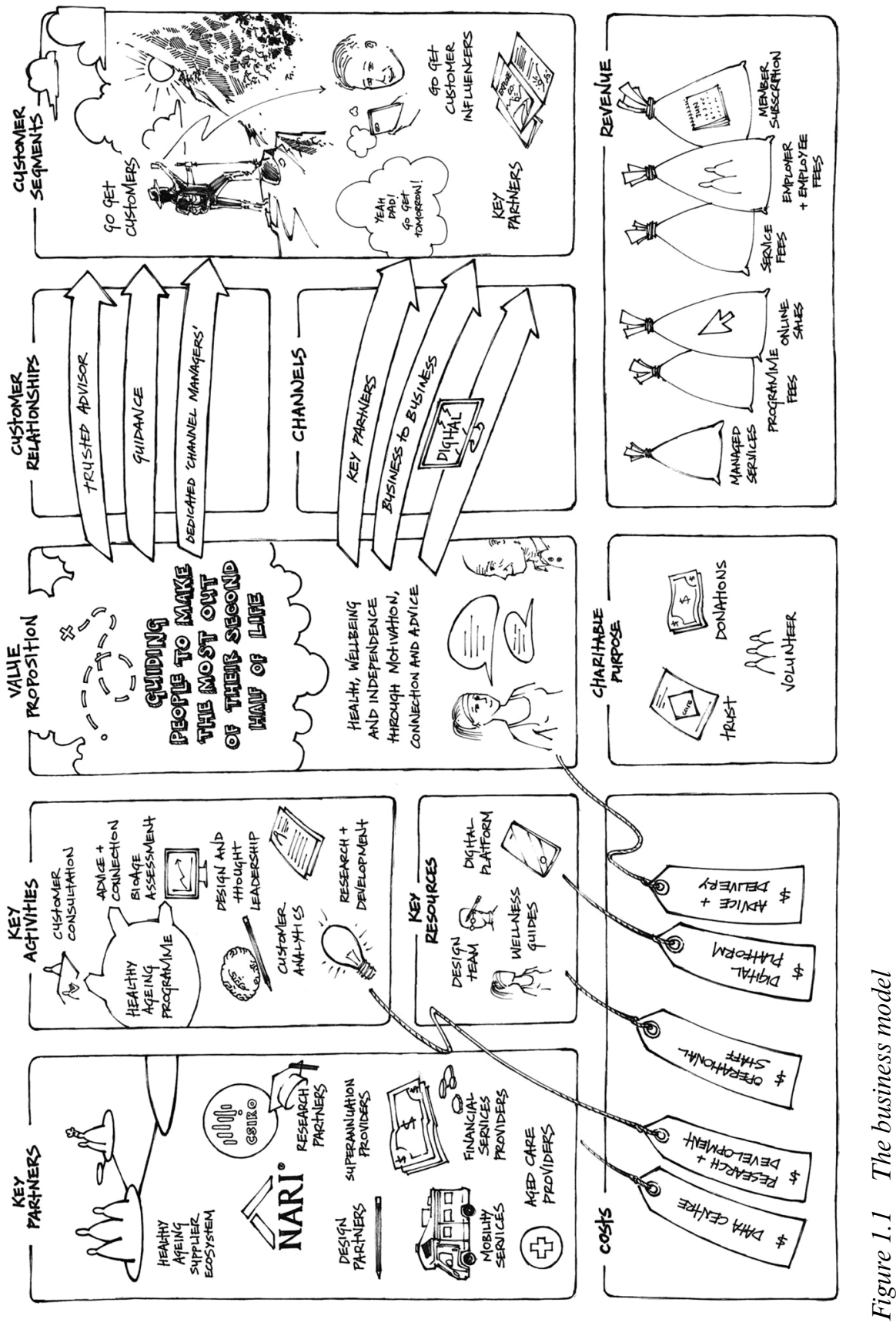


\section{DISCUSSION}

This chapter outlines three separate cycles of action research along with their respective purposes; these being demonstrate, conceptualize and implement. During the initial stages of research it was revealed that the long-term sustainability of the non-profit aged care provider's business model was in decline, and its value proposition was no longer relevant or compelling. The most prevalent challenges to be met by the organization were:

- government reforms resulting in changes to the funding structure;

- increasingly savvy customers with higher expectations and a disinterest for the current offering;

- risk of consolidation due to an undifferentiated offering;

- financially unsustainable business model;

- workforce challenges including relatively low pay rates and high rates of turnover; and

- risk of digital disruption from new market entrants.

In the face of these challenges, failing to design a new and compelling value proposition would see the organization as a non-relevant contender in aged care provision. Additionally, incremental forms of innovation typical to the aged care industry would be unsuitable in holistically addressing emerging challenges. Driving radical innovation to address these challenges obligates a top-down approach to innovation that is driven from within the company (Wrigley, 2013). As such, the first cycle of research had two distinctive goals: (1) to establish a suitable base of evidence for driving innovation within the participating organization and (2) to demonstrate the value of a design-led approach to innovation to the participating organization.

Addressing these goals saw the organization conduct a customer segmentation study, analysis of the aged care sector and a series of narrative focus groups. The former two methods (1) highlighted the homogeneity of existing aged care offerings, along with the risks in maintaining an undifferentiated business model. Furthermore, these methods indicated that the existing aged care offering was unsuitable in meeting emerging customers' needs, and that the majority of the aged demographic did not perceive value in the existing offering. The narrative focus groups (2) were found to be appropriate for building empathy, and challenging assumptions surrounding the emerging needs of the aged demographic. However, the narratives were not an appropriate platform for conceptualization, and, due to a relatively small sample size, were not sufficient for demonstrating the 
value of the design methodology to anyone beyond one or two individuals who were directly involved in their execution.

Having accumulated a rich base of customer insights during the first cycle of research the organization went about conceptualizing a customercentric business model. In conjunction with Prahalad and Ramaswamy's (2004, p. 5) thinking, the organization did not act autonomously in the design of the new offering. Instead, key stakeholders in the aged demographic were engaged as active designers during the second cycle of research. This ensured that the offerings were grounded in customer needs, and allowed the conceptual models to create mutual value for both the future user and organization. The second phase of design also saw the organization shift from a divergent to a convergent approach to thinking through a series of focus groups, with each focus group belonging to one of three typologies featuring a predefined purpose.

Using the customer insights from Cycle I as a base of evidence, the first focus group was designed predominantly to identify white space opportunities in the aged care sector. However, being heavily structured, the focus group was only conducive in further developing existing predetermined ideas and areas of opportunity. Nonetheless, it resulted in a clearer understanding of emerging opportunities in the aged care space, and accentuated where design could be used to disrupt or innovate existing offerings. The purpose of the second set of focus groups was ideation. Building on areas of opportunity from the first focus group, participants were engaged as designers through a facilitated conversation. While most participants were eager to engage in discussion, they often pursued somewhat unrelated or irrelevant lines of thought as the topic of conversation was inherently personal. The purpose of the third set of focus groups was to further define the final business model concepts through a co-design approach, with bare-bones visuals being utilized to describe the most basic aspects of each concept. This approach was found to be effective in stimulating conversation. Additionally, as a result of the visuals conveying a minimal amount of information, the approach was found to neither constrain nor lead the conversation. Having engaged a more significant number of internal stakeholders, this cycle of research made the design process more transparent, and was more suitable in showcasing the design methodology's value to the organization.

Finally, the third cycle of research saw the participating organization fully develop and implement the business model prototype conceptualized through this study. While the design-led approach to innovating the aged care providers' business model was found to excel in the conceptual stages of design, further development and implementation proved to be more challenging. From a business to business lens, an abundance of external 
providers were interested in partnering to deliver the new business model. However, from a people perspective, recruiting both customers and staff was challenging. The design-led approach was consequently supplemented by additional methodologies closer to the prototype launch.

\section{The Framework}

A variety of design methods were used in the scope of the action research study presented in this chapter, with the amalgamation of these methods resulting in the design of a customer-centric business model. During the undertaking of this study, the aged care provider did not have the benefit of a fully formed innovation framework to follow. The innovation framework developed through this study can be seen in Figure 1.2.

Following this framework, the first cycle of design seeks to create a better understanding of a service organization's customer and market, and utilize a customer-centric approach to test whether the organization's

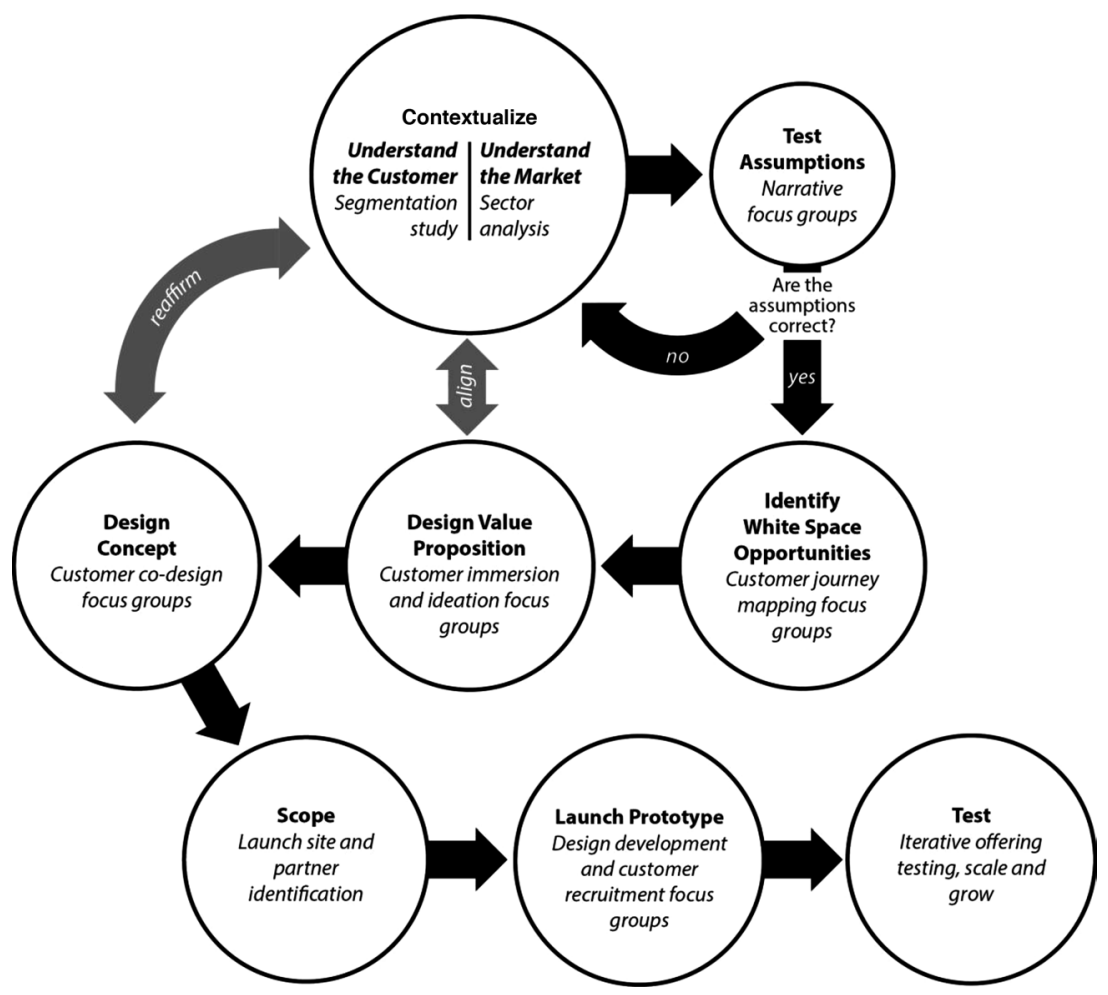

Figure 1.2 The design framework 
assumptions are aligned to the needs exhibited by its customers. The second cycle sees the organization set out to identify white space opportunities, design a value proposition aligned to the needs of its customer, and co-design a business model offering with its target customer segment. During the third cycle the organization scopes the competitive environment, identifies potential partners, develops the prototype, and launches the initial prototype with a small group of test users.

\section{CONCLUSION}

Organizations in the aged care sector are currently under pressure from more than just a sheer increase of customers. A need to respond to changing legislative requirements, increased expectations from customers and increasing likelihood of shortage of appropriate experienced staff are also contributing to instability within this sector, causing organizations to question the value offered through their services. In response to these change drivers, the organization featured in this research sought to redefine its business model. The study began by questioning where the organization was and where it was headed, creating a clear future vision and a clear idea of what the organization wanted to become. The organization then went about designing a customer-centric business model by challenging the value it offered to market.

Initial stages saw the organization gathering a deep understanding of its stakeholders, internal and external environment, and capturing a rich base of customer insights that would act as a foundation for future innovations. Leveraging on this initial scope of work, the organization set out to identify white space opportunities for business model innovation, conceptualize what form the model could take and co-design a model and an underlying value proposition aligned to the needs of the aged demographic. Following conceptualization the model was further developed and prototyped. In conjunction with dominant literature, the design-led approach to innovation revealed that consumers are becoming increasingly discontented with the traditional value proposition of aged care providers, and to offer a truly attractive solution to market providers must now wholesomely address all relevant dimensions of their customers' wellbeing; shifting away from the predominantly reactive and medical model of care provision.

This chapter outlines and details the approach utilized by a non-profit aged care organization in attempting to design a new compelling business model that addresses the emerging needs and challenges of an ageing population. While no generalized approach exists for organizations to innovate and respond to a dynamic market, this chapter offers a concrete 
method to drive innovation in the design of new business models. As this approach was only tried in the context of aged care, future research should assess the applicability of the design framework outlined in this chapter in addressing social challenges in alternative market dynamics.

The backdrop of an ageing population has seen an evolution in thinking about the way design is approached for the emerging demands of the aged demographic (Clarkson et al., 2003). There is increasing understanding of the enormous value design adds to business, especially in areas not traditionally seen as the domain of design (Martin, 2009). It is ever more clear that incorporating design in the form of business strategy is a method for overcoming common structural flaws in service provision and value offering (UK Design Council et al., 2013). As the aged care sector is a dynamic environment, the agenda driving this research must exceed a one-time solution. The implementation of a single new business model cannot be guaranteed to indefinitely address emerging customers' needs. The true organizational challenge, and opportunity for future research, lies in embedding the design capability within organizations so they might drive innovation internally.

\section{REFERENCES}

Ballinger, C., L. Yardley and S. Payne (2004), 'Observation and action research', in D.F. Marks and L. Yardley (eds), Research Methods for Clinical and Health Psychology, London: Sage, pp. 102-22.

Blythe, M.A., A.F. Monk and K. Doughty (2005), 'Socially dependable design: the challenge of ageing populations for HCI', Interacting with Computers, 17 (6), 672-89.

Boyatzis, R.E. (1998), Transforming Qualitative Information: Thematic Analysis and Code Development, Thousand Oaks, CA: Sage.

Burns, L.R. (2012), The Business of Healthcare Innovation (2nd edn), Cambridge: Cambridge University Press.

Carlopio, J. (2009), 'Creating strategy by design', Design Principles and Practices: An International Journal, 3 (5), 155-66.

Christensen, K., G. Doblhammer, R. Rau and J.W. Vaupel (2009), 'Ageing populations: the challenges ahead', Lancet, 374 (9696), 1196-208.

Clare, S., H. Tingle and J. Twiss (2010), 'Aging populations', Public Management, 92 (4), 14-19.

Clarkson, J., R. Coleman, S. Keates and C. Lebbon (eds) (2003), Inclusive Design: Design for the Whole Population, London: Springer.

Cox, G. and Z. Dayan (2005), Cox Review of Creativity in Business: Building on the UK's Strengths, TSO, UK.

Dell'Era, C., A. Marchesi and R. Verganti (2010), 'Mastering technologies in design-driven innovation', Research Technology Management, March-April, 12-24. 
Dwyer, D. (2011), 'Experiences of registered nurses as managers and leaders in residential aged care facilities: a systematic review', International Journal of Evidence-Based Healthcare, 9 (4), 388-402.

Goldstein, S., R. Johnston, J. Duffy and J. Rao (2002), 'The service concept: the missing link in service design research?', Journal of Operations Management, 20 (2), 121-34.

Green, L., J. Howells, I. Miles, PREST and CRIC (2001), Services and Innovation: Dynamics of Service Innovation in the European Union, Manchester: University of Manchester Press.

Guion, L., D. Diehl and D. McDonald (2011), 'Triangulation: establishing the validity of qualitative studies', Florida, CA: University of Florida Press.

Joffe, H. and L. Yardley (2004), 'Content and thematic analysis', in D.F. Marks and L. Yardley (eds), Research Methods for Clinical and Health Psychology, London: Sage, pp. 56-69.

King, D. (2007), 'Rethinking the care-market relationship in care provider organisations', Australian Journal of Social Issues, 42 (2), 199-212.

King, D., K. Mavromaras, Z. Wei et al. (2012), The Aged Care Workforce 2012: Final Report, Canberra: Australian Government Department of Health and Ageing.

Maffei, S., B. Mager and D. Sangiorgi (2005), 'Innovation through service design: from research and theory to a network of practice. A user's driven perspective', in Joining Forces, Helsinki, Finland: University of Art and Design Helsinki.

Martin, R. (2009), The Design of Business: Why Design Thinking is the Next Competitive Advantage, Boston, MA: Harvard Business Press.

Maurya, A. (2012), Running Lean: Iterate from Plan A to a Plan that Works (2nd edn), California: O'Reilly.

Miles, M., A. Huberman and J. Saldaña (1994), Qualitative Data Analysis: A Methods Sourcebook (3rd edn), Thousand Oaks, CA: Sage.

Mulgan, G. and D. Albury (2003), Innovation in the Public Sector, Strategy Unit, Cabinet Office, London.

Nusem, E., A. Defries, C. Wrigley and J. Matthews (2014), 'Customer journey and experience canvas', in M. Laakso and K. Ekman (eds), Proceedings of the 10th International NORD Design Conference, Espoo, Finland: Design Society, pp. 406-15.

Nusem, E., A. Defries and C. Wrigley (2015), 'Applying design-led innovation in a not for profit aged care provider to create shared value', in G. Muratovski (ed.), Design for Business, Bristol: University of Chicago Press/Intellect Books, pp. 172-93.

Osterwalder, A. and Y. Pigneur (2010), Business Model Generation: A Handbook for Visionaries, Game Changers, and Challengers, Hoboken, NJ: John Wiley \& Sons.

Prahalad, C. and V. Ramaswamy (2004), 'Co-creation experiences: the next practice in value creation', Journal of Interactive Marketing, 18 (3), 5-13.

Shin, J. and G.E. McClomb (2013), 'Top executive leadership and organizational innovation', Administration in Social Work, 22 (3), 1-21.

Swan, W. (2010), Australia to 2050: Future Challenges, Canberra: Commonwealth of Australia.

UK Design Council, Danish Design Centre, Wales Design and Aalto University (2013), Design for Public Good, UK Design Council.

Watt, D. (2007), 'On becoming a qualitative researcher: the value of reflexivity', The Qualitative Report, 12 (1), 82-101. 
Weerawardena, J. and G.S. Mort (2001), 'Learning, innovation and competitive advantage in not-for-profit aged care marketing: a conceptual model and research propositions', Journal of Nonprofit \& Public Sector Marketing, 9 (3), $37-41$.

Wrigley, C. (2013), 'Educating the "Design Innovation Catalyst" for Change', in K. Sugiyama (ed.), Consilience and Innovation in Design Proceedings and Program, Vol. 1, Tokyo: Shibaura Institute of Technology, pp.3547-57. 